\title{
STATISTICAL Distribution FUNCTIONS FOR BONE STRENGTH OF LEGHORN LAYERS
}

\author{
J. H. Wilson \\ MEMBER \\ ASAE
}

\begin{abstract}
Shear strength tests were conducted on tibia, humerus, and radius bones from white leghorn layers to establish the type of statistical distribution function that best fits poultry bone strength data. The results indicated that a threeparameter Weibull distribution best described the maximum shear force and stress of the tibia and a shifted log-normal distribution best described the maximum shear stress of the radius. None of the chosen distributions (normal, log-normal, Weibull, and gamma) fit the data for the maximum shear force of the radius or humerus. Because of the nonnormal nature of the distribution of poultry bone strength, nonparameter statistics should be used to analyze the data. KEYwORDS. Bone strength, Layers, Log-normal, Weibull, Normal.
\end{abstract}

\section{INTRODUCTION}

$\mathrm{M}$ any hypothesis-testing procedures are based on the assumption that random samples are selected from a normal population. Most of these tests are still reliable when the sample distribution is nearly normal or the sample size is large. These tests are called parametric methods. A second method, nonparametric, assumes no knowledge of the distribution of the population but only assumes that the population is continuous. In general, parametric statistics are more efficient than nonparametric if either could be used, but if serious departures from normality occur, then nonparametric methods are much more efficient. A more efficient procedure makes better use of the data and enables one to get a better estimate with a small sample size. If a $95 \%$ confidence limit is constructed for nonnormal data using parametric procedures, the actual limit may be only $91 \%$ (Ryan et al., 1985).

Harner and Wilson (1985) conducted shear and threepoint bending tests on the tibia and femur from broilers to establish the type of statistical distribution that best fits poultry bone strength data. Results of their investigation indicated that a log-normal distribution best described the mechanical properties of the tibia and a normal distribution best described the properties of femur. Harner and Wilson also noted that the ultimate shear stress of the femur could have been described using a normal, log-normal, or Weibull distribution. The chi-squared goodness of fit test was used in their analysis and the normal distribution was

Article was submitted for publication in February 1991; reviewed and approved for publication in May 1992.

The author is James H. Wilson, Dept. of Agricultural Engineering, Virginia Tech, Blacksburg. chosen because it had the lowest value for the chi-squared statistics even though all three distributions were suitable. The maximum log-likelihood test was not used as a second method to select the best fit.

A review of the literature gave no indication as to the type of expected distribution of the mechanical properties of bone from laying hens. Therefore, this study was undertaken to determine the distributions that best describe the mechanical properties of bones from layers.

\section{MATERIALS AND METHODS}

One-hundred and twelve tibiae, radii, and humeri bones from white leghorn laying hens from the same flock were tested to determine the form of the distribution function. Shear tests were performed using a double shear block apparatus (Wilson et al., 1984). The shear force was exerted over a $12.7 \mathrm{~mm}$ section at the center of the diaphysis. These tests resulted in the maximum shear force and stress being evaluated for each bone.

The normal, shifted log-normal, three-parameter Weibull, and gamma distributions were fitted to each set of data. The data were plotted and analyzed using the graphic distribution analysis (GDA) package developed by Worley et al. (1990).

\section{RESULTS AND DISCUSSION}

The choice of the distributions that best fit the data sets were based on visual examination of the histogram with the distribution superimposed, the chi-square goodness of fit test, and maximum log-likelihood. A visual assessment can sometimes illustrate an obvious weakness in the chosen distribution. For the chi-square tests, a P-statistic is determined and is an indicator of the critical point at which the test would reject the hypothesis that the data were from the chosen distribution. A large P-statistic indicates a good fit. Maximum log-likelihood is used when a visual and a chi-square test both indicate more than one distribution could fit the data. The distribution with the highest value of the maximum log-likelihood would then be considered the best fit.

Figure 1 shows a comparison of the distributions that were considered as possible distributions for the maximum shear stress of the tibia. Figure 1-D shows the output for the attempt to fit a normal distribution to the data. Note that the P-statistic (Table 1) is 0.07 , which indicates that the chi-square test would not reject the fit at $\alpha=0.05$, but would reject it at $\alpha=0.10$. Using a visual assessment, figure 1-D shows a poor fit in the lower tail, thus indicating a questionable fit. Figure 1-A shows the output 

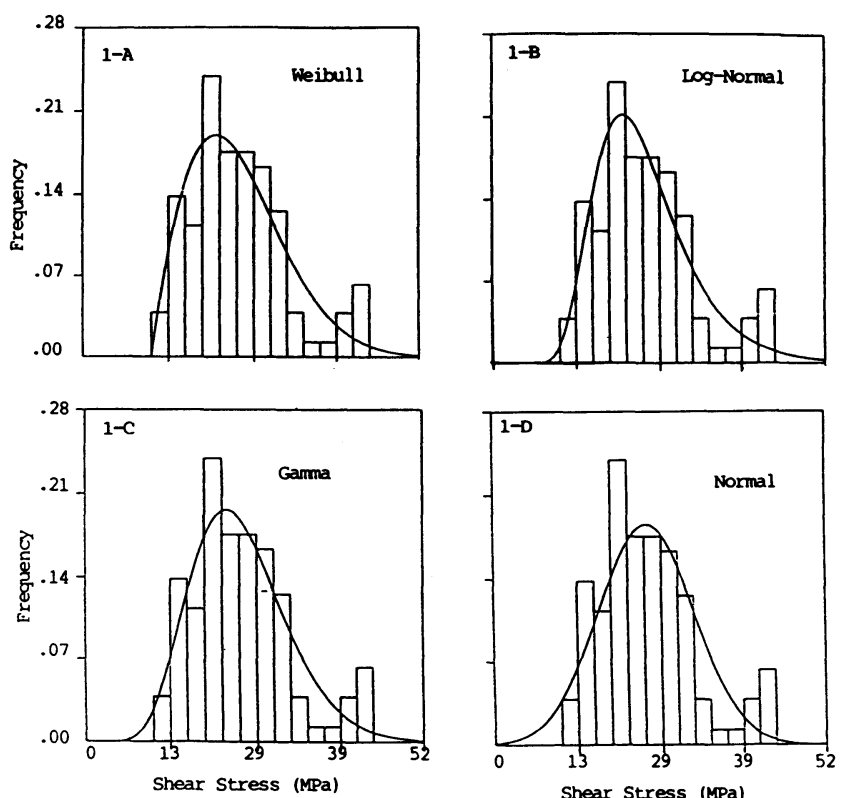

Figure 1-Comparison of statistical distributions for maximum shear stress of the tibia.

for fitting a three-parameter Weibull distribution to the same data set. The chi-square P-statistic is 0.29 indicating a good fit. A visual assessment of figure 1-A also shows a good fit. The log-normal $(P<0.1)$ and gamma $(P=0.02)$ were rejected as possible distributions.

TABLE 1. Statistical distribution analysis of bone strength of leghorn layers

\begin{tabular}{|c|c|c|c|c|}
\hline $\begin{array}{l}\text { Bone } \\
\text { Type }\end{array}$ & $\begin{array}{l}\text { Mechanical } \\
\text { Property }\end{array}$ & Distribution & $\begin{array}{c}\text { P- } \\
\text { Value }\end{array}$ & $\begin{array}{l}\text { Log-Like- } \\
\text { lihood }\end{array}$ \\
\hline \multirow[t]{8}{*}{ Tibia } & Maximum force & Normal & $<0.01$ & -239 \\
\hline & & 3-P Weibull & 0.26 & -227 \\
\hline & & Shifted log-normal & $<0.01$ & -229 \\
\hline & & Gamma & 0.27 & -230 \\
\hline & Maximum stress & Normal & 0.07 & -231 \\
\hline & & 3-P Weibull & 0.29 & -223 \\
\hline & & Shifted log-normal & $<0.01$ & -224 \\
\hline & & Gamma & 0.02 & -225 \\
\hline \multirow[t]{8}{*}{ Radius } & Maximum force & Normal & 0.04 & -240 \\
\hline & & 3-P Weibull & 0.06 & -233 \\
\hline & & Shifted log-normal & 0.04 & -234 \\
\hline & & Gamma & 0.08 & -234 \\
\hline & Maximum stress & Normal & 0.17 & -236 \\
\hline & & 3-P Weibull & 0.17 & -233 \\
\hline & & Shifted log-normal & 0.87 & -236 \\
\hline & & Gamma & 0.87 & -233 \\
\hline \multirow[t]{8}{*}{ Humerus } & Maximum force & Normal & 0.01 & -211 \\
\hline & & 3-P Weibull & 0.01 & -211 \\
\hline & & Shifted log-normal & 0.05 & -208 \\
\hline & & Gamma & 0.01 & -207 \\
\hline & Maximum stress & Normal & $<0.01$ & -190 \\
\hline & & 3-P Weibull & 0.05 & -182 \\
\hline & & Shifted log-normal & 0.47 & -182 \\
\hline & & Gamma & 0.03 & -183 \\
\hline
\end{tabular}


log-normal $(P<0.01)$ were rejected as possible distributions.

Figure 3 shows the results of fitting a log-normal $(P=0.87)$ and a normal $(P=0.17)$ distribution to the data for the maximum shear stress of the radius. Even though the chi-squared test indicated that both distributions could be used to model the data, a visual assessment would suggest using the log-normal. None of the distributions considered in the investigation fits the data for the maximum shear force of the radius or of the humerus (Table 1). The maximum shear stress of the humerus could be fitted using a log-normal $(P=0.47)$ distribution.

A summary of Table 1 indicates that poultry bone strength data is not normal and one must be careful how the data is analyzed. Because of the nonnormal distribution, the actual level of significance in an analysis of variance may be higher than that obtained by assuming a normal distribution (Steel and Torrie, 1960). It is suggested that nonparametric statistics be used to analyze this type of data.

\section{REFERENCES}

Harner, J. P., III and J. H. Wilson. 1985. Bone strength statistical distribution functions for broilers. Poultry Sci. 64:585-587.

Ryan, B. F., B. L. Joiner and T. A. Ryan, Jr. 1985. Minitab Handbook, 2nd Ed. Boston, MA: PWS-Kent Publ. Co.

Steel, R. G. D. and J. H. Torrie. 1960. Principles and Procedures of Statistics. New York: McGraw-Hill Book Co.

Wilson, J. H., K. L. Bledsoe, J. L. Baker and P. F. Scanlon. 1984. Mechanical properties of river otter limb bones. Zoo Biology 3:27-34.

Worley, J. W., J. A. Bollinger, F. E. Woeste and K. S. Kline. 1990. GDA: A computer aid to distribution fitting for input modeling. Applied Engineering in Agriculture 6(3):367-371. 